\title{
FATORES CAUSADORES DE NAUFRÁGIOS NO ARQUIPÉLAGO DE FERNANDO DE NORONHA, PERNAMBUCO, BRASIL: DO SÉCULO XVI AO XXI
}

\author{
Natalia Silva \\ Carlos Riosii
}

\begin{abstract}
Resumo: Este trabalho teve como base uma pesquisa bibliográfica que quantifica o número de naufrágios e identifica, na maioria das vezes, os fatores de soçobros ocorridos no mar adjacente ao arquipélago de Fernando de Noronha ao longo de 500 anos. Além disso, contextualiza tais naufrágios em seus respectivos séculos e resgata parte da história trágico-marítima de cada sítio de naufrágio por meio de pesquisa histórica. A análise apresenta as informações obtidas e processadas, organizadas em uma tabela, sobre o local estudado, bem como identifica as suas respectivas nacionalidades. $O$ resultado apontou para 21 naufrágios de 9 nacionalidades diferentes, bem como foi possível identificar 06 fatores de naufrágios, preponderando o hidrometeorológico. Palavras-Chave: Arqueologia Subaquática; Fatores Causadores de Naufrágios; Naufrágio; Arquipélago de Fernando de Noronha.
\end{abstract}

\begin{abstract}
This work was based on a bibliographical research that quantifies the number of shipwrecks and identifies, most of the time, the factors of shipwrecks occurred in open sea or near the archipelago of Fernando de Noronha during 500 years. In addition, it contextualizes such shipwrecks in their respective centuries and rescues part of the tragic-maritime history of each shipwreck site through historical research. The analysis presents the information obtained and processed, organized in a table, about the place studied, as well as identifies their respective nationalities. The result pointed to 21 wrecks of 9 different nationalities. With regard to the factors causing shipwreck, as well as it was possible to identify 06 factors, preponderating the hydrometeorological. Keywords: Underwater Archaeology; Wreck Factors; shipwreck; Fernando de Noronha Archipelago.
\end{abstract}

\footnotetext{
i Arqueóloga

ii Docente do Departamento de Arqueologia da Universidade Federal de Pernambuco - UFPE
} 
Introdução

A Arqueologia Subaquática é um instrumento de grande importância para esclarecer fatos obscuros ou até mesmo dúbios dos episódios da historiografia passada ou presente. 0 arqueólogo subaquático, na maioria das vezes, lida com vestígios do que um dia foi uma embarcação com todos os seus acessórios, equipamentos, andainas e palamentas, independente do que relata a historiografia, uma vez que não se pode avaliar o quão fidedigno foi o escritor ao escrever sobre determinado assunto. Só com a utilização do arqueólogo mergulhador e das metodologias e técnicas empregadas por esse ramo da Arqueologia é que se podem explicar episódios anônimos ou dúbios da história (Rios, 2010).

Por outro lado há uma importante parte do trabalho que antecede o mergulho, a pesquisa bibliográfica que é utilizada para coletar e contrastar informações sobre o objeto de estudo que, nesse caso, são os naufrágios que ocorreram no Arquipélago de Fernando de Noronha desde o século XVI até o XXI.

O Arquipélago de Fernando de Noronha (AFN) está localizado nas coordenadas geográficas $03^{\circ}$ $51^{\prime} 13.71^{\prime \prime} \mathrm{S} / 032^{\circ} 25^{\prime} 25.63^{\prime \prime}$ W (Figura 1) foi, provavelmente, descoberto por Gaspar de Lemos, em 1500. Inicialmente denominada de ilha de São João da Quaresma, possivelmente por estar no período litúrgico que antecede a Páscoa cristã (Borges, 2007).

Nas missões de reconhecimento ordenadas pelo rei de Portugal a costa do Brasil, entre 1501 a 1504, sob o comando de Gonçalo Coelho, ocorreu o primeiro naufrágio registrado em diário de bordo no Brasil, onde a nau capitânia São Lourenço, soçobrou ao colidir com penedos daquele arquipélago (Pereira da Costa, 1983; Berger, 1975; Borges, 2007).

O primeiro a descrever o arquipélago foi Américo Vespúcio, que tomou parte na expedição de Gonçalo Coelho. O fato de já ser chamada Ilha de Fernão de Noronha pelo Frei Vicente do Salvador, tal como hoje é conhecida, está justificado por provir do nome do primeiro donatário de Capitania Hereditária do Brasil, Fernão de Loronha ou Fernão de Noronha, após doação de D. Manuel I, em 16 de fevereiro de 1500 (Borges, 2007). 


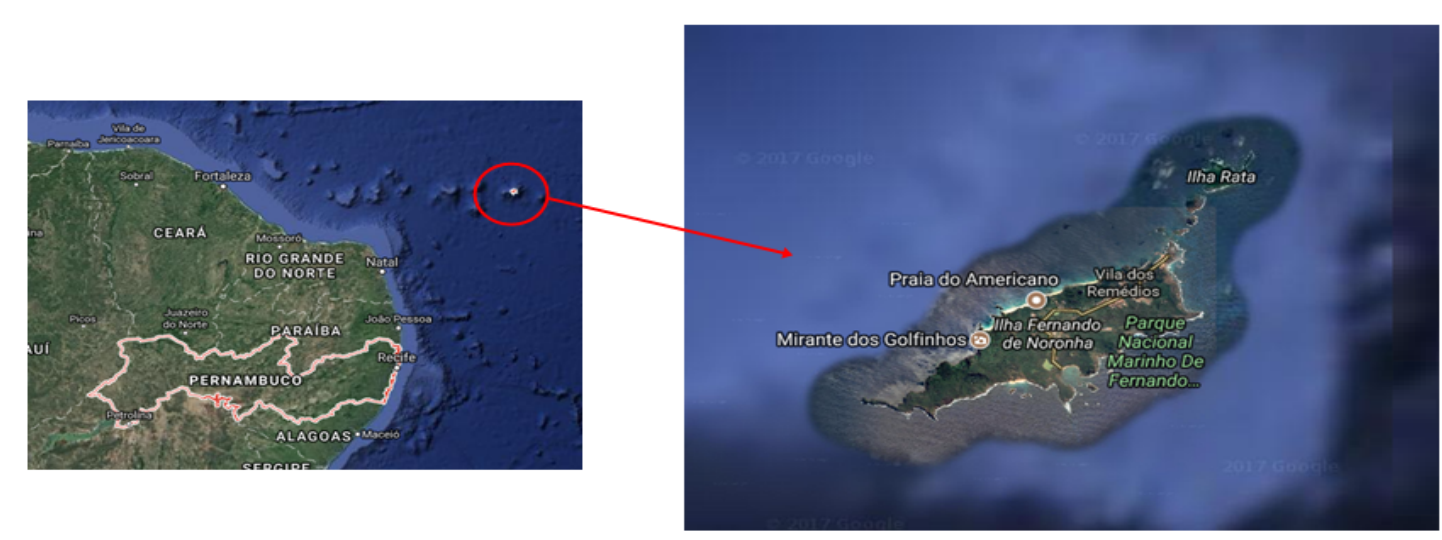

Figuras 01: Parte da costa NE com a localização do Arquipélago e detalhe do Arquipélago de Fernando de Noronha. Fonte: Google Earth, 2018.

A história do arquipélago pode ser escrita a partir das diversas invasões. As ilhas foram tomadas algumas vezes: nomeadamente em 1534 por ingleses; de 1556 até 1612 por franceses; de 1628 a 1635 pelos holandeses, voltando ao controle português em 1700 para ser, novamente, conquistada pelos franceses em 1736 e definitivamente ocupada pelos portugueses em 1737 (Borges, 2007).

Nas divisões territoriais do Brasil, datadas de 31 de dezembro de 1926 a 21 de dezembro de 1937, Fernando de Noronha, por questões históricas, apesar de não estar no mar adjacente ao Estado de Pernambuco, aparece como distrito do município do Recife. (Borges, 2007).

O então Território Federal de Fernando de Noronha foi criado em 09 de fevereiro de 1942, pelo Decreto-Lei Federal $n^{\circ} 4.102$, desmembrado do Estado de Pernambuco e passou a ser administrado pelo Estado-Maior das Forças Armadas (EMFA) até 05 de outubro de 1988, quando foi reincorporado à Pernambuco.

Nesse contexto, desde o período do seu descobrimento até a atualidade, o Arquipélago de Fernando de Noronha foi palco de naufrágios de navios e embarcações de diversos tipos e nacionalidades, cujos fatores causadores para cada século permaneciam desconhecidos.

Apesar de o Brasil não ser signatário da Convenção da Unesco de 2001, que versa sobre a proteção do patrimônio cultural subaquático, a mesma disserta que, dentre as competências do Estado estão as atribuições de: "tomar as medidas necessárias para elaborar, manter e atualizar um inventário de patrimônio cultural subaquático"; "garantir eficazmente a proteção, a conservação, a apresentação e gestão desse patrimônio"; e "fomentar a pesquisa e educação nesse âmbito" (Unesco, 2001, p.11). Infelizmente, em pleno século XXI, não se tinha 
conhecimento do quantitativo exato de sítios de naufrágios e, de acordo com alguns sites de mergulho, só se sabia a localização de 5 sítios arqueológicos subaquáticos (Sinau, 2018).

O presente trabalho se justifica na medida em que resgata parte da história trágico-marítima de Pernambuco por meio de levantamento do número de navios soçobrados entre os séculos $\mathrm{XVI}$ e XXI, bem como identifica as causas dos naufrágios para cada século, subsidiando assim futuros trabalhos voltados para a Carta Arqueológica de Naufrágios de Pernambuco. O estudo possibilita, também, a inclusão de tais naufrágios no Parque de Naufrágios do AFN, o que acarretará na criação de novos circuitos de turismo arqueológico tendo como ferramenta a Arqueologia Subaquática.

O trabalho tem como objetivo geral identificar os fatores causadores de naufrágios ocorridos no mar adjacente no arquipélago de Fernando de Noronha ao longo de 500 anos, contextualizando-os dentro de seus respectivos séculos. A pesquisa também visa quantificar, por meio de investigação bibliográfica, o número de naufrágios ocorridos no mar territorial, assim como plotar, dentro das possibilidades, latitude e longitude em carta náutica de cada um desses sítios de naufrágio.

\section{Método}

Para atingir os objetivos foram feitas pesquisas nas bibliotecas da UFPE (de História e de Arqueologia), da Fundação Joaquim Nabuco, do Instituto Arqueológico, Histórico e Geográfico Pernambucano, bem como foi solicitado auxílio ao Departamento do Patrimônio Histórico e Documentação da Marinha do Brasil. Também foram realizadas buscas em diversos sites, um deles foi de grande ajuda, denominado "Naufrágios do Brasil", criado por Maurício Carvalho.

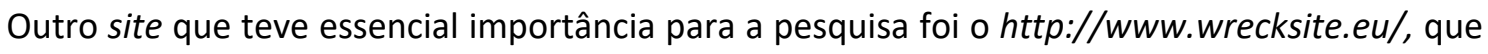
contém informações sobre naufrágios de todo o mundo.

Para identificação dos fatores causadores de naufrágios foi utilizada a metodologia de RIOS (2010), onde há 8 fatores que combinados ou não, podem causar o soçobro de uma embarcação, sendo eles:

Fator Humano - Podem ser enquadradas como Imperícia, Imprudência e Negligência, bem como quando existe a intenção ou vontade deliberada do afundamento, denominado de Proposital. Na maioria dos casos de afundamento há relação com esse primeiro fator. 
Fator Bélico - É causado por embates entre belonaves, colisão com artefato bélico fixo ou flutuante (mina) ou sabotagem, ocasionando explosões, abalroamentos e/ou explosões propositais com o intuito de aniquilar ou pôr, temporariamente, o inimigo fora de combate.

Fator Patológico - Acontece quando a embarcação fica sem o mestre ou o piloto por questões de doença, que os levavam à morte ou os deixam incapacitados de continuarem o trabalho. Esse fator é de difícil ocorrência nos dias atuais, mas nos primórdios das grandes navegações transoceânicas era muito comum de acontecer.

Fator Hidrometeorológico - É o desconhecimento das correntes, das mudanças bruscas dos regimes de ventos, da existência de monções e outros fenômenos meteorológicos, que faz com que a embarcação fique sem governo (perdendo mastros ou o leme), levando o navio a colidir com arrecifes, baixios, coroas, penedos, escolho ou altos fundos, ou perda da calafetagem devido ao embate das ondas, causando a entrada de água por essas aberturas no casco. Sendo esse fator não tão comum na atualidade, devido aos avanços tecnológicos e à formação do pessoal responsável pela embarcação.

Fator Cartográfico - Ocorre devido ao mau levantamento, desconhecimento da cartografia local ou crescimento de um recife de coral ou aparecimento de uma coroa de sedimento marinho ou aluvional, escolho ou casco soçobrado não posicionado em carta, ocasionando colisão, encalhe, varação de terra, água aberta, explosão, incêndio e/ou naufrágio. É incomum de ocorrer nos dias de hoje devido ao avanço tecnológico na elaboração das cartas náuticas.

Fator Logístico - Ocorre devido ao excesso de carga, má peiação ou má estivação (no porão, no convés ou mesmo no interior do contêiner), quer no granel, quer na carga geral, sem observar ainda a adequabilidade da embalagem, pondo em risco a estabilidade do navio, a integridade da própria carga e das pessoas de bordo, acarretando em alijamento de parte ou da totalidade da carga, banda, emborcamento e/ou naufrágio.

Fator Estrutural - Ocorre pela falta de manutenção, reparo imediato ou má construção da embarcação, acarretando em avaria de equipamento, peça, acessório, aparelho ou material de bordo, tendo como consequência água aberta, encalhe, alijamento e/ou naufrágio.

Fator Fortuito - É a colisão da embarcação e/ou seus apêndices e/ou acessórios, contra qualquer objeto fixo ou flutuante, que não seja outra embarcação ou artefato bélico, contra 
pessoa (mergulhador ou banhista) ou animal vivo ou morto, acarretando em encalhe, água aberta, banda, alijamento, emborcamento e/ou naufrágio.

\section{Resultados}

Para o melhor entendimento foram confeccionados dois quadros. 0 quadro 1 , contém o nome da embarcação, nacionalidade, ano de naufrágio, fator causador de naufrágio e século de afundamento e o quadro 2 contém informações como: nome e nacionalidade das embarcações, localização e coordenadas geográficas, tipo de embarcação e informações sobre a tripulação dos naufrágios.

Quadro 1: Relação das embarcações, cronologia e fator causador de naufrágio.

\begin{tabular}{|l|l|l|l|}
\hline \multicolumn{1}{|c|}{ NOME EMBARCAÇÃO/NACIONALIDADE } & ANO & \multicolumn{1}{c|}{$\begin{array}{c}\text { FATOR CAUSADOR DE } \\
\text { NAUFRÁGIO }\end{array}$} & SÉCULO \\
\hline 1 - São Lourenço (Caravela de G. Coelho), PT & 1503 & Cartográfico & XVI \\
\hline 2- Nome desconhecido, NL & 1629 & Humano/Proposital & XVII \\
\hline 3- Nome desconhecido, NL & 1629 & Humano/Proposital & XVII \\
\hline 4 - Bougaiville, FR & 1838 & Hidrometereológico & XIX \\
\hline 5- Álvaro, BR & 1909 & Cartográfico & XX \\
\hline 6 - SS Floride, FR & 1915 & ? & XX \\
\hline 7- Gray's Harbor, USA & 1918 & ? & XX \\
\hline 8 -Vapor Aylestone, UK & 1926 & Hidrometereológico & XX \\
\hline 9- Eleani Stathatos, GR & 1929 & Humano/Proposital & XX \\
\hline 10- Maria Stathatos, GR & 1937 & Humano/Proposital & XX \\
\hline 11- Themone Stathatos, GR & 1937 & Humano/Proposital & XX \\
\hline 12- SS Alcoa Rambler, USA & 1942 & Bélico & XX \\
\hline 13- Corveta V-17, BR & 1983 & Cartográfico & XX \\
\hline 14- Mar da Amônia, BR & 2013 & Hidrometereológico & XXI \\
\hline 15- Juca II, BR & 2013 & Hidrometereológico & XXI \\
\hline 16- Bita I, BR & 2013 & Hidrometereológico & XXI \\
\hline 17- Jota Pelaça, BR & 2013 & Hidrometereológico & XXI \\
\hline 18- Sabinos, BR & 2013 & Hidrometereológico & XXI \\
\hline 19- WY Rodrigues, BR & 2015 & Estrutural & XXI \\
\hline 20- O Alquimista, BR & 2017 & Hidrometereológico & XXI \\
\hline 21- Naufrágio do canal da Rata, ? & $?$ & ? & ? \\
\hline
\end{tabular}


Quadro 2: Nacionalidade da embarcação, localização, tipo e tripulação

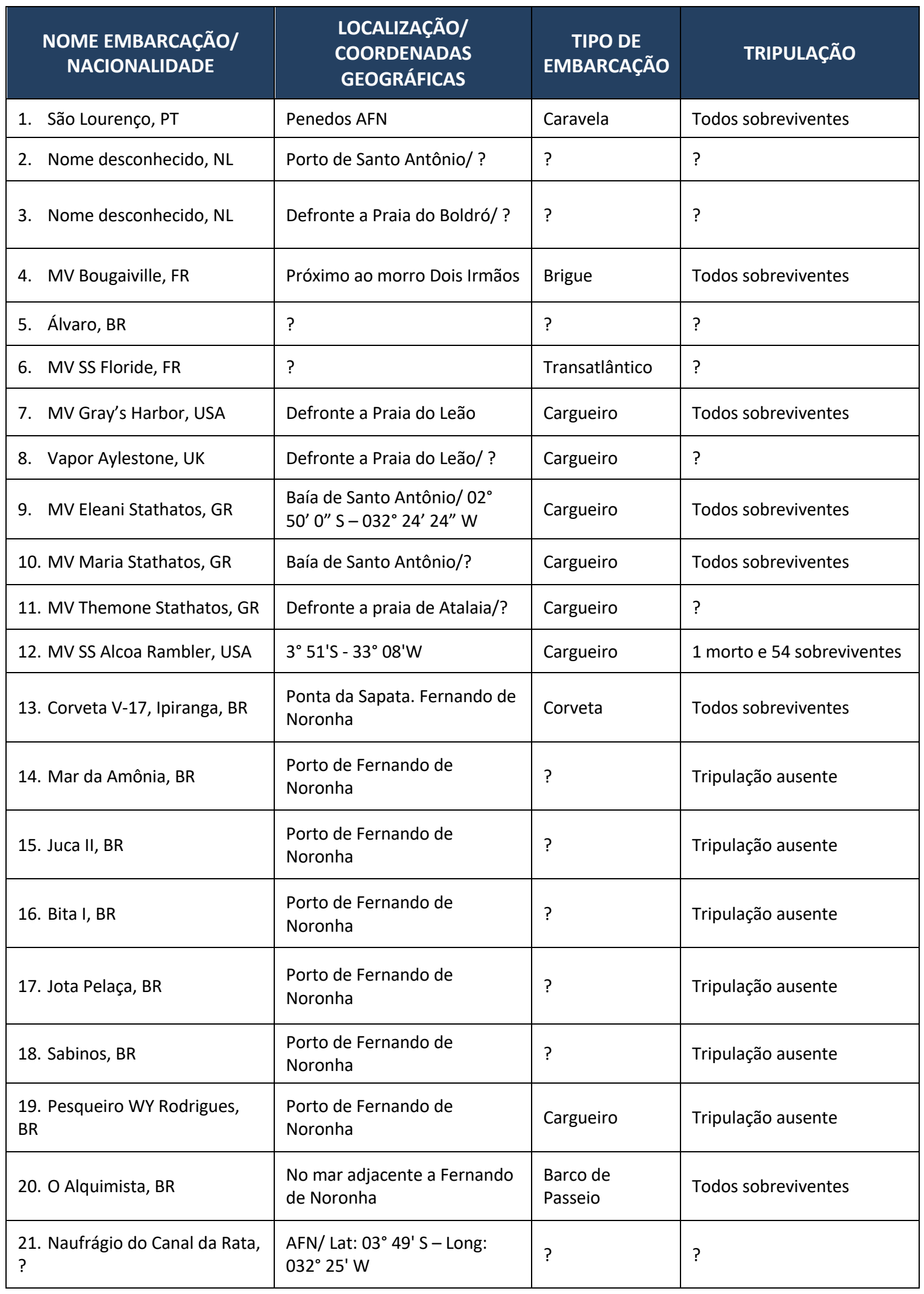




\section{Análise dos Quadros}

1 - O único naufrágio encontrado no século XVI teve o fator cartográfico como razão do soçobro. A embarcação era uma caravela de nome São Lourenço, nau capitânia de Gonçalo Coelho e que soçobrou em 10 de agosto de 1503, e que vem a ser o primeiro naufrágio brasileiro registrado em diário de bordo (Pereira da Costa, 1983; Berger, 1975; Borges, 2007). De acordo com Simão de Vasconcelos (1977), em 10 de junho de 1503, por ordem do Rei de Portugal, D. Manoel, parte de Lisboa, com destino ao Brasil, uma expedição naval composta de seis caravelas, sob o comando do capitão Gonçalo Coelho. O propósito de tal Armada era obter o máximo de informações da costa brasileira, especialmente no que diz respeito às suas correntes litorâneas, monções, possíveis locais para a fixação de portos, qualidade da terra e das pessoas que a habitavam, visando a sua futura ocupação e extração de riquezas.

Segundo Marieta Borges (2007), depois da partida de Portugal, a Armada seguiu para sudeste, em direção a Serra Leoa, para escapar das calmarias equatoriais do Atlântico e então seguiu para o Brasil encontrando, a $3^{\circ}$ para o Sul, uma ilha no meio do mar, extremamente alta e notável, que não tinha mais que duas léguas de comprimento e uma de largura, com um bom ancoradouro, desabitada e com muitos águas doces e correntes, bastante árvores e aves. Depois de dois meses de viagem, ocorre o primeiro naufrágio da Armada que colidiu com um dos parcéis de Fernando de Noronha.

Partindo do princípio que a Armada zarpou de Portugal em direção ao Brasil, logo a abordagem ao Arquipélago de Fernando de Noronha seria, a princípio, por $\mathrm{N}$, assim a possibilidade do naufrágio ter ocorrido no parcel localizado na extremidade NE da ilha da Rata. A atual localização da embarcação permanece desconhecida, abrindo espaço para algumas hipóteses acerca do seu local de naufrágio, assim como o desenvolvimento de futuras pesquisas sobre o assunto.

2 e 3- As duas embarcações Holandesas, do século XVII, foram afundadas propositalmente em 1629. As informações sobre esses dois naufrágios é escassa sabendo-se, até o momento, apenas suas localizações aproximadas. A primeira no porto de Santo Antônio e a segunda defronte à praia do Boldró (Borges, 2007). 
4- Já no século XIX, o brigue Francês Bougaiville naufragou em 1838, sabe-se até o momento apenas que a tripulação foi retirada do mar por presidiários, logo não foi distante da costa (Borges, 2007).

5- O Álvaro soçobrou em 1909, chocando-se com os espigões, caracterizando o fator cartográfico, existindo várias possibilidades do lugar do soçobro (Borges, 2007).

6 - O SS Floride tinha como propósito transporte de pessoas (transatlântico), naufragou em 1915, por motivos desconhecidos (Wrecksite, 2017).

7- O Gray's Harbor naufragou em 22/08/1918, estava sem carga e todos os 23 tripulantes se salvaram alcançando a praia (Wrecksite, 2017).

8- Em 8 de julho de 1926, o Aylestone, um vapor inglês, encalhou e naufragou na llha Fernando Noronha, quando viajava de Rosário, AR, para o Reino Unido, UK, com uma carga de milho, possivelmente, entre a cota de 3 a $6 \mathrm{~m}$ de profundidade (Borges, 2007).

9,10 e 11 - 3 navios gregos de uma mesma companhia naufragaram: O primeiro deles foi o Eliane Stathatos, em 1929, o segundo foi o Maria Stathatos (Figura 2), em 1937, que teve sua tripulação salva pelo porta-aviões Westfalem e o último foi o Themone Stathatos, também em 1937, defronte à praia de Atalaia (Borges, 2007). 


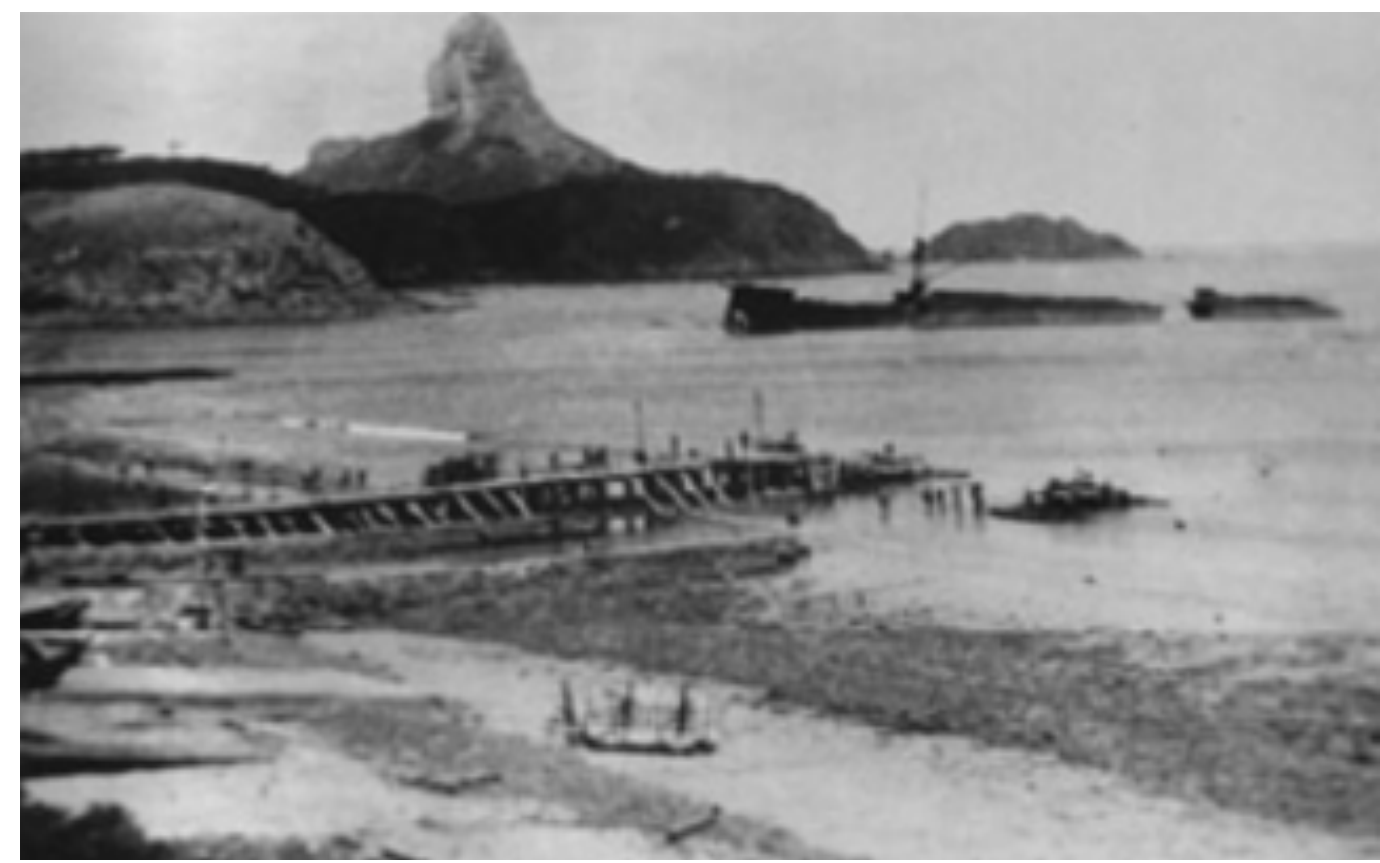

Figura 2: Maria Stathatos encalhado paralelo a praia na Baía de Santo Antônio. Fonte: Silva,1992.

12- O USSB Mercer Victory foi um cargueiro americano de 5.500 toneladas, construído em 1919, pela Merchant Shipbuilding, navio foi comprado pela Alcoa Steamship Company e renomeado SS ALCOA RAMBLER. Em 15 de dezembro de 1942, quando viaja de Nova lorque para Trindade e de lá para Santos levando uma carga de 7.243 toneladas de carvão, ele foi torpedeado e afundado pelo submarino alemão $U-174$, possivelmente, estava passando ao largo, em águas profundas (Wrecksite, 2017).

13- A Corveta Ipiranga, naufragou em outubro de 1983 , ela fazia viagem de patrulhamento pela costa Nordeste do Brasil, quando se chocou com o cabeço da Sapata. Após a colisão a V17 demorou cerca de 8 horas para afundar completamente, enquanto isso, várias embarcações aproximaram-se da corveta para auxiliar nos trabalhos de descarregamento e retirada de diversas peças e dos tripulantes. Está a 67 m de profundidade (Borges, 2007).

14, 15, 16, 17 e 18 - O fator causador desses soçobros foi o hidrometeorológico. Esses naufrágios ocorreram devido a grandes ondas que origem no fenômeno conhecido como 
"swell" que é formado por uma tempestade oceânica e teve origem na costa Leste dos Estados Unidos e se propagou para o Atlântico Sul (G1 Globo.com, 2017).

19- WY Rodrigues - O barco de pesca afundou na madrugada do dia 24 de abril de 2015, quando estava ancorado no Porto de Santo Antônio. Ninguém estava a bordo e não houve vítimas. O dono da embarcação em uma entrevista que concedeu a um jornal acredita que uma peça se desprendeu, causando um vazamento. Por falta de manutenção houve então o naufrágio da embarcação (G1 Globo.com, 2015).

20 - Embarcação de turismo 'Alquimista', que soçobrou no dia 18 de fevereiro de 2017. O mar estava revolto no momento, o barco manobrava no Porto de Santo Antônio quando entrou uma série de ondas e naufragou. Sendo assim, o fator hidrometereológico se faz presente mais uma vez (G1 Globo.com, 2017).

21 - Naufrágio do Canal da Rata - Não foi possível encontrar muitos dados sobre esse naufrágio, apenas há a informação de que ele está enterrado, cujo material do casco era de madeira e tinha uma carga de telhas de cerâmica, o que sugere o transporte de material do Recife ou Natal para o AFN (Naufrágios do Brasil, 2017).

Durante a pesquisa, não foram encontrados naufrágios relacionados ao século XVIII.

Gráfico 1: Fatores causadores de naufrágios

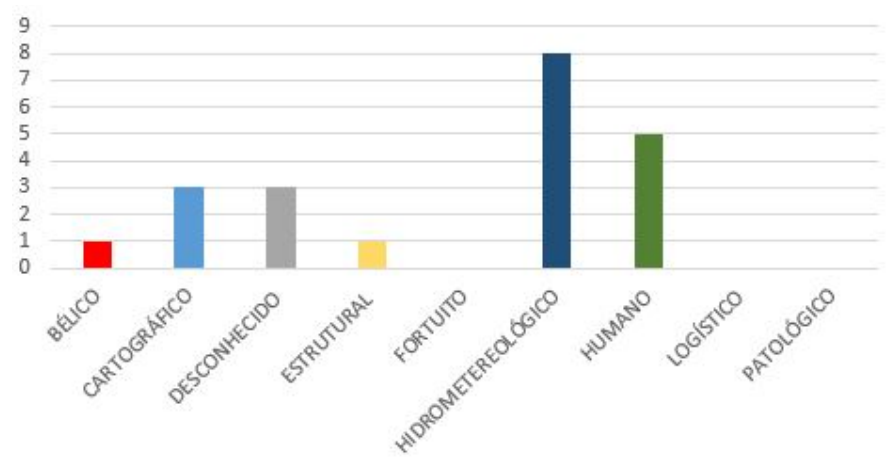


Como é possível observar, o fator Hidrometereológico é a maior causa de naufrágios, seguido pelo Humano. Esse resultado era de se esperar, pois há fenômenos que afetam o arquipélago frequentemente como o "swell", que causam grandes ondas, podendo ter força suficiente para ocasionar o naufrágio de uma embarcação.

Outro resultado esperado foi o aparecimento com maior frequência do fator humano que, geralmente, está associado aos outros fatores. O fator Cartográfico fica em igual número com os naufrágios que não se sabe a causa. Esse desconhecimento é fruto da falta de informações sobre os soçobros e informações dos proprietários das embarcações.

Em seguida, o fator Bélico com 1 naufrágio, que ocorreu justamente no período da $2^{\text {a }}$ Grande Guerra Mundial. Por último o fator Estrutural como causa de apenas 1 naufrágio, que ocorreu no presente século e, não menos importante, o conhecimento da existência de embarcações naufragadas no século XXI, para enriquecer a histórica trágico-marítima do país, assim como para utilização de pesquisas para futuros estudos. Os outros fatores citados neste texto como Fortuito, Logístico e Patológico não foram percussores de naufrágios.

\section{Considerações Finais}

Foi possível compilar um grande número de informações sobre os naufrágios que ocorreram no AFN. Foram identificados 21 naufrágios, sabendo-se a nacionalidade de 20 desses soçobros. Apesar do conhecimento dessas nacionalidades não foi possível identificar em todos os naufrágios os seus fatores causadores, fato esse que pode ser dar pela falta de registro do naufrágio, havendo a possibilidade de nenhum membro da tripulação ter sobrevivido ao sinistro e de não haver testemunha alguma na hora da tragédia - o que pode ser o caso do século XVIII, onde não foi encontrado, até o momento, registro de naufrágios, o que não elimina a possibilidade de ter acontecido. Também foi possível identificar o ano do sinistro de 20 dos 21 naufrágios ocorridos. O trabalho também enriqueceu a história trágico-marítima brasileira, na medida em que trouxe informações sobre importantes embarcações que fizeram parte da história do país. 


\section{Referências}

ARAÚJO, J. G. 2008. Naufrágios e afundamentos na costa brasileira. Salvador: JM Gráfica e Editora.

BORGES, M. 2014. Fernando de Noronha: cinco séculos de história. Recife: Editora Universitária.

BOXER, C. R. 2002. O império marítimo português 1415-1825. São Paulo: Companhia das Letras.

BRITO, B. G. (Org).1998. História trágico-marítima. Rio de Janeiro: Lacerda Editores/Contraponto Editora.

CAMINHA, J. C. 1980. História trágico-marítima. Rio de Janeiro: Bibliex.

CHERQUES, S. 1999. Dicionário do mar. São Paulo: Globo.

G1 GLOBO.COM Disponível em: <http://g1.globo.com/pernambuco/blog/viver-noronha/post/barco-de-turismonaufraga-em-fernando-de-noronha.html > Acesso em: 17 de Junho de 2017.

G1 GLOBO.COM Disponível em: http://g1.globo.com/pernambuco/blog/viver-noronha/post/barco-de-pescaafunda-em-fernando-de-noronha.html Acesso em: 17 de Junho de 2017.

GUEDES, M. J. 1986. História Marítima do Brasil. Rio de Janeiro: Ministério da Marinha, Serviço de Documentação.

LIMA, M. O. 1975. Pernambuco e o seu desenvolvimento histórico. Recife: CEPE.

MADEIRA, A. 2005. Livro dos naufrágios: ensaio sobre a história trágico-marítima. Brasília: Universidade de Brasília.

NAUFRÁGIOS DO BRASIL. Disponível em: < https://www.naufragiosdobrasil.com.br/naufragios.htm\#noronha>. Acesso em: 17 de Junho de 2017.

PARRA FILHO, D.; SANTOS, J. A. 1998. Metodologia científica. São Paulo: Futura.

PEREIRA DA COSTA, F. A. 1983. Anais Pernambucanos. $2^{\circ}$ ed. Recife: Fundarpe.

RIOS, C. 2010. Arqueologia Subaquática: identificação das causas de naufrágios nos séculos XIX e XX na costa de Pernambuco. Tese (Doutorado em Arqueologia). Centro de Filosofia e Ciências Humanas, Universidade Federal de Pernambuco, Recife.

RIOS, C. 2011. Subsídios para a Arqueologia Subaquática: Fatores Causadores de Naufrágios. Rio de Janeiro: Revista Navigator, $\mathrm{n}^{\circ} 6$.

SILVA, M. J. L. 1992. Fernando de Noronha: Imagens do passado. 1992.

VASCONCELOS, S. 1977. Crônica da Companhia de Jesus. Rio de Janeiro: Vozes.

UNESCO. Disponível em: <http://www.unesco.org/culture/por/heritage/laws/conv_patsubaqu_portu.pdf>. Acesso em 12 de Maio de 2017.

WRECKSITE. Disponível em: <http://www.wrecksite.eu/chartDetails.aspx?1056>. Acesso em 1 de Junho de 2017. 